\begin{tabular}{|c|l|}
\hline Title & Adsorptive removal of geosmin by ceramic membrane filtration with super-powdered activated carbon \\
\hline Author(s) & Matsui, Y oshihiko; A izawa, Takako; Kanda, Fumiaki; Nigorikawa, Naoko; Mima, Satoru; Kawase, Yuji \\
\hline Citation & $\begin{array}{l}\text { Journal of Water Supply : Research and Technology, A QUA, 56/6-7), 411-418 } \\
\text { https:/doi.org/L0.2166/aqua.2007.017 }\end{array}$ \\
\hline Issue Date & $2007-09$ \\
\hline Doc URL & http://hdl.handle.net/2115/30269 \\
\hline Type & article \\
\hline File Information & JWSRTA 56-6-7.pdf \\
\hline
\end{tabular}

Instructions for use 


\title{
Adsorptive removal of geosmin by ceramic membrane filtration with super-powdered activated carbon
}

\author{
Yoshihiko Matsui, Takako Aizawa, Fumiaki Kanda, Naoko Nigorikawa, \\ Satoru Mima and Yuji Kawase
}

\begin{abstract}
Tap water free from unpleasant taste and odour is important for consumer satisfaction. We applied a super-powdered activated carbon (S-PAC) and microfiltration (MF) system to the removal of geosmin, a taste- and odour-causing compound. We used a specially pulverised PAC with a submicron particle size, much smaller than the normal PAC (N-PAC) particle size, as an adsorption pretreatment agent. MF and adsorption pretreatment with S-PAC removed geosmin with considerably greater efficiency and at a much lower dosage rate than with N-PAC. An S-PAC dosage of $2 \mathrm{mg} / \mathrm{L}$ was equivalent to an N-PAC dosage of more than $20 \mathrm{mg} / \mathrm{L}$ in the treatment of reagent-geosmin-spiked feed water - a dosage saving of $90 \%$, with better removal. In experiments with feed water spiked with cultured Anabaena and geosmin, geosmin removal was attained with S-PAC at a dosage $10 \%$ of that of N-PAC. The superiority of S-PAC in removing naturally occurring geosmin from raw water was also confirmed. However, the dosage saving in this case was $75 \%$. S-PAC also helped attenuate trans-membrane pressure increases in both physical backwash and chemical cleaning cycles. No significant trans-membrane pressure increase was observed during 4 months of MF operation with S-PAC addition, suggesting that S-PAC particles did not clog or foul the membrane.
\end{abstract}

Key words | adsorption, algae, MF, odour, PAC, taste

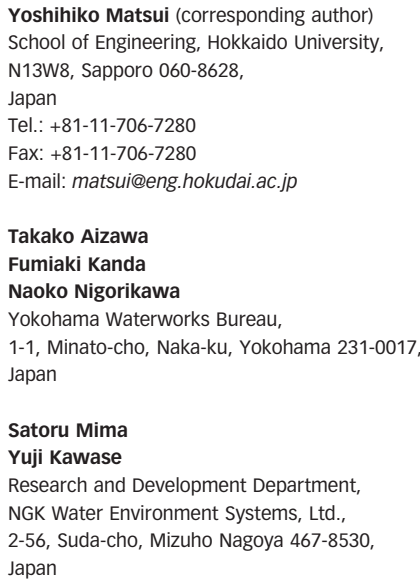

\section{INTRODUCTION}

Taste and odour in drinking water are persistent problems for many water supply entities. In Japan, the raw water sources of about 80 water supply entities, which supply about $20 \%$ of the Japanese population, contain taste- and odour-causing substances, most of which are produced by algae (Japan Water Works Assoc. 2006; Ministry of Health, Labour and Welfare 2006). Although treatment processes such as ozonation and activated carbon treatment are implemented in drinking water treatments to mitigate the problems caused by taste and odour compounds in water, about 3 million consumers still experience an earthy-musty taste and odour in their drinking water. The presence of doi: $10.2166 /$ aqua.2007.017 geosmin and 2-methylisoborneol (2-MIB), metabolites of blue-green algae and actinomycetes, causes customer complaints because these substances impart a detectable earthy-musty taste and odour at even the very low concentration of $10 \mathrm{ng} / \mathrm{L}$ (Japan Water Works Assoc. 200I). The Japanese drinking water quality standard enacted in 2004 requires 2-MIB and geosmin concentrations to be less than this value.

Although ozonation is an effective treatment option for the control of taste and odour compounds, formation of the hazardous by-product bromate must be controlled (Proc. IWSA International Workshop 1993; Lefebvre et al. 1995). 
Granular activated carbon (GAC) adsorption is also effective in removing these compounds at water treatment plants; however, hygienic and aesthetic problems arise from enhanced microbial growth on the filters and the presence of invertebrates, mostly nematodes, in the filters, impairing the quality of the drinking water (Castaldelli et al. 2005).

PAC treatment is a traditional method of controlling taste and odour, but the removal efficiency is limited by the maximum allowable dosage applied to the PAC injector. Moreover, a very long PAC-water contact time is essential to ensure full utilisation of the adsorptive capacity of the PAC. When PAC contact time is insufficient, the full capacity of the PAC is wasted and costs become excessively high. In fact, the operators of many water treatment plants use PAC to remove taste and odour compounds but are concerned about the high costs involved. Microfiltration (MF) and ultrafiltration membrane water treatment can include PAC adsorption before the membrane filtration. This is a simple treatment method, with a low capital cost and small space requirement, in which PAC is directly added to the membrane filtration influent and the PAC particles with adsorbed dissolved substances, such as taste and odour compounds, are finally removed by membrane filtration (Baudin et al. 1993; Laine et al. 200I). However, this method also has the disadvantage of inefficient adsorption capacity resulting from the short PAC-water contact time. This adsorption inefficiency results from antagonism between adsorption and the membrane components; the advantageous small space requirement of membrane filtration is incompatible with the PAC requirement of long PAC-water contact time (i.e., in a large contactor) to ensure high adsorption efficiency. This antagonism can be resolved by reducing PAC particle size, thus enhancing the adsorption kinetics. However, PAC cost per volume increases with decreasing particle size as the product is sieved into smaller fractions (Clark et al. 1996). Recently, Matsui et al. (2004, 2005, 2006) proposed the application of an extremely small, micro-ground PAC (called here a super-PAC [S-PAC]), with a particle size of less than $1 \mu \mathrm{m}$, to treatment before ceramic MF to attain improved removal of naturally occurring organic matter. The S-PAC adsorption-membrane process is also expected to improve taste and odour control. We describe here the results of membrane pilot plant experiments in which
S-PAC was applied before ceramic membrane filtration to better remove geosmin from the water.

\section{$\overline{\text { MATERIALS AND METHODS }}$}

\section{Powdered activated carbon}

S-PAC in the MF experiments was obtained by micro-grinding thermally activated, wood-based PAC (Taikou-W, Futamura Chemical Industries Co., Ltd., Gifu, Japan) in a wet bead-mill. To determine the effects of PAC size and the effectiveness of S-PAC in MF, we used both the S-PAC and as-received normal PAC (N-PAC). Particle size distributions of the PACs (Figure 1) were determined by using laser-light scattering instruments (LMS-30; Seishin Enterprise Co., Ltd., Tokyo, Japan). The median size of the as-received N-PAC was $7.6 \mu \mathrm{m}$, and about $70 \%$ by volume of the PAC particles were larger than $5 \mu \mathrm{m}$. Pulverisation yielded a median size of $0.65 \mu \mathrm{m}$. The effective diameter was $0.22 \mu \mathrm{m}$, and $70 \%$ by volume of the S-PAC particles were less than $1 \mu \mathrm{m}$.

\section{Membrane filtration pilot plant}

A small-membrane filtration pilot plant is located within the Kawai Water Purification Plant in Yokohama. The plant has three parallel MF lines that can be operated independently under different operational conditions (Figure 2). Each line has a small membrane module containing a tubular, ceramic

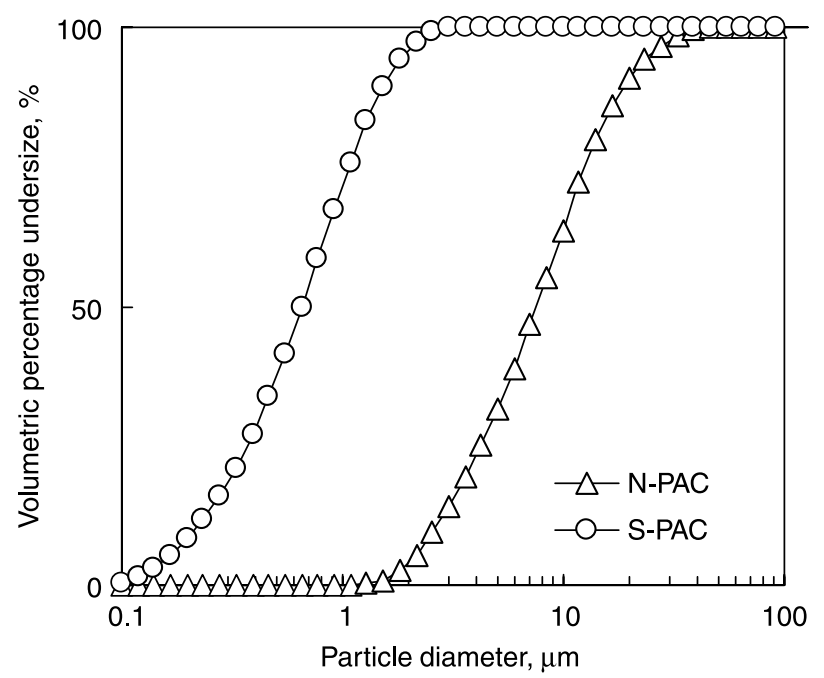

Figure 1 | Particle size distribution of as-received N-PAC and S-PAC used for MF pilot plant experiments. 


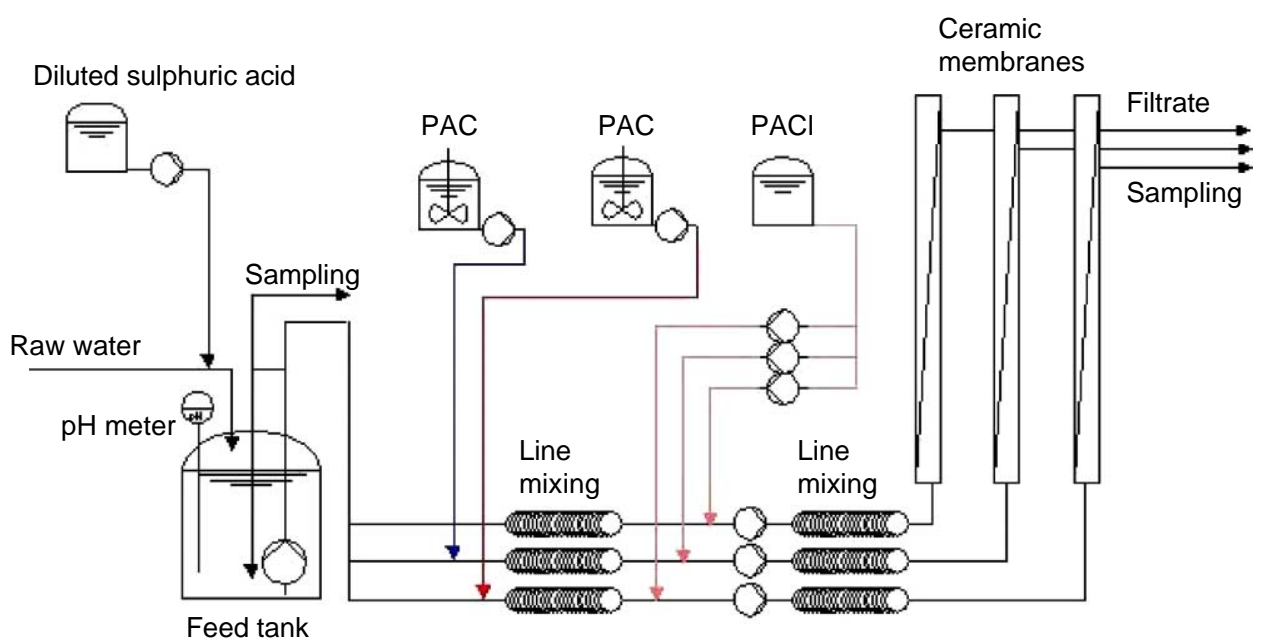

Figure 2 | Setup of small-membrane MF pilot plant.

monolith membrane (nominal pore size, $0.1 \mu \mathrm{m}$; filtration area, $0.4 \mathrm{~m}^{2}$; membrane diameter, $30 \mathrm{~mm}$; membrane length, $1 \mathrm{~m}$; NGK Insulators, Ltd., Nagoya, Japan). In the membrane filtration experiments, raw water from Lake Sagami was first introduced into the MF feed tank, from which it was distributed to the three MF lines. The S-PAC and N-PAC were added at the inlets of two of the tube reactors at a controlled dosage rate. After 2 min of PAC contact in the tube reactors, the coagulant, poly-aluminium chloride $(\mathrm{PACl}$, Hieisyouten Co., Ltd., Aichi, Japan), was added and the water was mixed for another $2 \mathrm{~min}$. The flow of feed to the membrane module was configured in dead-end mode at a constant rate (filtration rate: either 0.125 or $0.167 \mathrm{~m} / \mathrm{h}$ ) inside the module by positive pressure, and the membranes were hydraulically backwashed every 3 or $4 \mathrm{~h}$, except in some of the short geosmin-removal experiments. During the long pilot run, most of the pilot plant operation did not coincide with seasonal blue-green algae production in Lake Sagami. Therefore, in all but two geosmin removal experiments, reagent geosmin $(100 \mathrm{mg} / \mathrm{L}-\mathrm{methanol}$, Kanto Chemical Co., Inc., Tokyo, Japan) or cultivated blue-green algae (Anabaena) suspension was added to the MF feed tank, which had been filled with raw water and then was disconnected from the raw water feed to avoid further feed water dilution.

After the small-membrane pilot plant had operated for 1 year, a large-membrane pilot plant was installed. The largemembrane plant has a large, tubular, ceramic monolith membrane for full-scale use (nominal pore size, $0.1 \mu \mathrm{m}$; filtration area, $25 \mathrm{~m}^{2}$; membrane diameter, $180 \mathrm{~mm}$; membrane

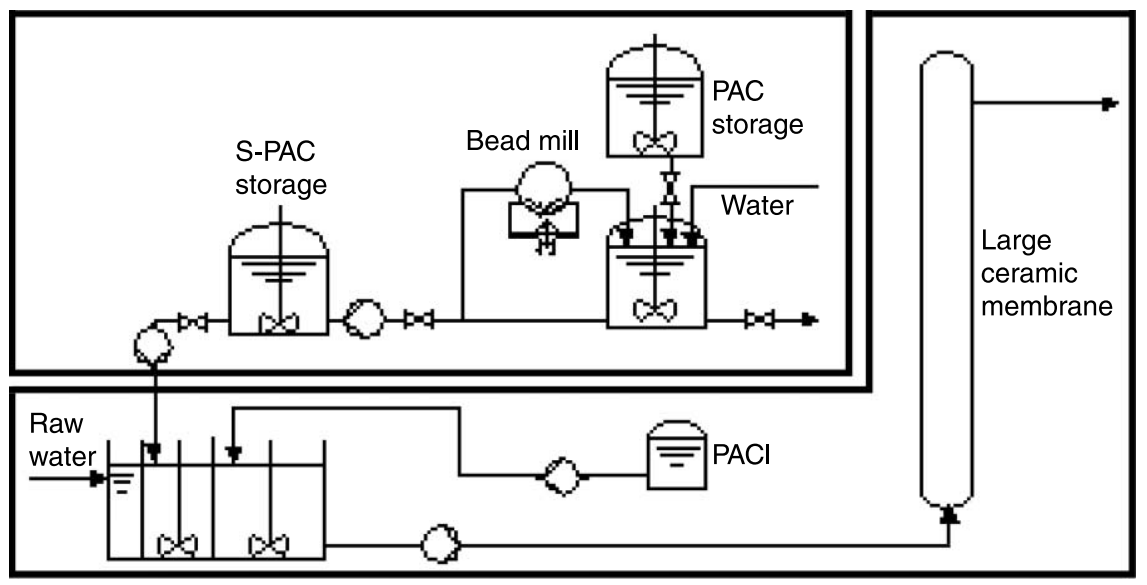

Figure 3 | Setup of on-site PAC pulveriser, feeder and large-membrane MF pilot plant. 
length, $1.5 \mathrm{~m}$; NGK Insulators, Ltd.) and an on-site automatic PAC feeder and wet bead-mill system (NGK Insulators, Ltd.) (Figure 3). N-PAC slurry was stored in a tank and fed into the wet bead-mill when the slurry level in the S-PAC storage tank decreased. S-PAC was added to a mechanical mixing tank and given a 3-min contact time, after which $\mathrm{PACl}$ was added at the next mixing tank and the water was mixed for another 6 min. The flow of feed to the membrane module was configured in dead-end mode at a constant rate (filtration rate: $0.125 \mathrm{~m} / \mathrm{h}$ ) inside the module by positive pressure, and the membrane was hydraulically backwashed every $4 \mathrm{~h}$.

\section{Geosmin and its analysis}

Anabaena sp., a geosmin-producing strain isolated from the water from Lake Sagami, had been grown in a 2-L flask of CT medium without mixing or aeration (Watanabe \& Ichimura I977). Cultures were incubated at $25^{\circ} \mathrm{C}$ in a growth cabinet under a 12-h light-12-h dark regime. The liquid phase geosmin concentration in the Anabaena solution was determined after gravity filtration of the solution by a fibreglass filter (nominal pore size, $1 \mu \mathrm{m})$. The total geosmin concentration was determined $30 \mathrm{~min}$ after the addition of sodium hypochlorite solution $(2,000 \mathrm{mg} \mathrm{Cl} / \mathrm{L})$ at $1 / 1,000 \mathrm{v} / \mathrm{v}$; the addition of sodium hypochlorite released geosmin in the Anabaena cells into the bulk water phase. The geosmin concentration was determined by headspace solid phase microextraction (SPME, Sigma-Aldrich Japan K.K., Tokyo, Japan) coupled with gas chromatography - time-of-flight mass spectrometry (GCTOF-MS, JEOL Ltd., Tokyo, Japan). The ions recorded in the selected-ion-monitoring (SIM) mode of TOF-MS had a massto-charge ratio $(\mathrm{m} / \mathrm{z})$ of $112.06274 \pm 50$ mmass.

\section{$\overline{\text { RESULTS AND DISCUSSION }}$}

Figure 4 shows the time-course variation of geosmin concentration in the filtrates of the small-scale MF plant with one filtration cycle (backwash interval $4 \mathrm{~h}$ ). In this experiment, the membrane feed water was spiked with reagent geosmin and the influent geosmin concentration was $514 \mathrm{ng} / \mathrm{L}$. N-PAC addition followed by MF did not show marked geosmin removal; the geosmin concentration was reduced by up to $200-300 \mathrm{ng} / \mathrm{L}$ (removal percentage

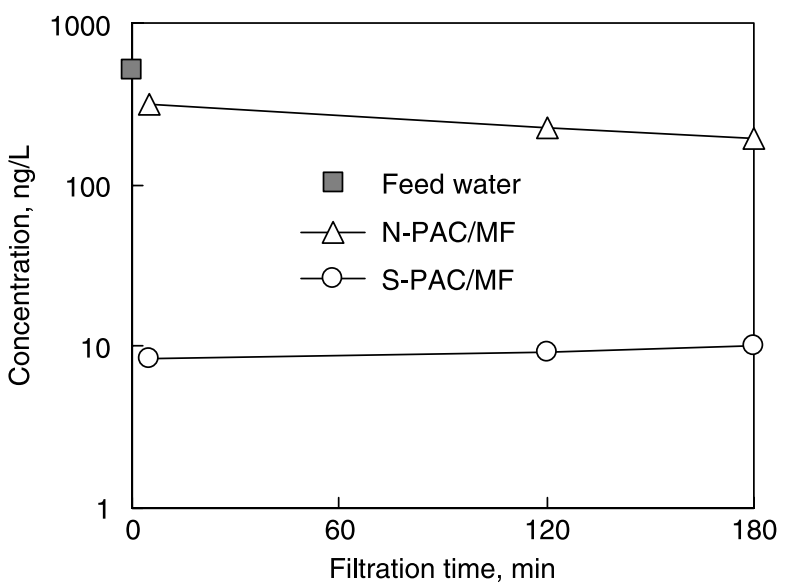

Figure 4 Time-course change of geosmin concentration in MF filtrate from treated reagent-geosmin-spiked water (PAC $2 \mathrm{mg} / \mathrm{L}, \mathrm{PACl} 1.3 \mathrm{mg}-\mathrm{A} 1 / \mathrm{L}$, MF flux $0.167 \mathrm{~m} / \mathrm{h}$, backwash interval $3 \mathrm{~h}$ ).

$<62 \%$ ). However, S-PAC addition at the same dosage rate as N-PAC, followed by $\mathrm{MF}$, reduced the geosmin concentration to less than $10 \mathrm{ng} / \mathrm{L}$ (removal percentage $>98 \%$ ), satisfying Japan's current stringent drinking water quality standard.

We experimented with several PAC dosage rates and investigated the relationships between PAC dosage and geosmin concentration in the membrane filtrate (Figure 5). The dosage required for N-PAC to reduce influent geosmin concentration from 241 to $5 \mathrm{ng} / \mathrm{L}$ was $20 \mathrm{mg} / \mathrm{L}$. An S-PAC dosage of $2 \mathrm{mg} / \mathrm{L}$ reduced the geosmin concentration to less than $2 \mathrm{ng} / \mathrm{L}$; this dosage was less than $10 \%$ of the required N-PAC dosage (probably about 6\% according to extrapolated experimental

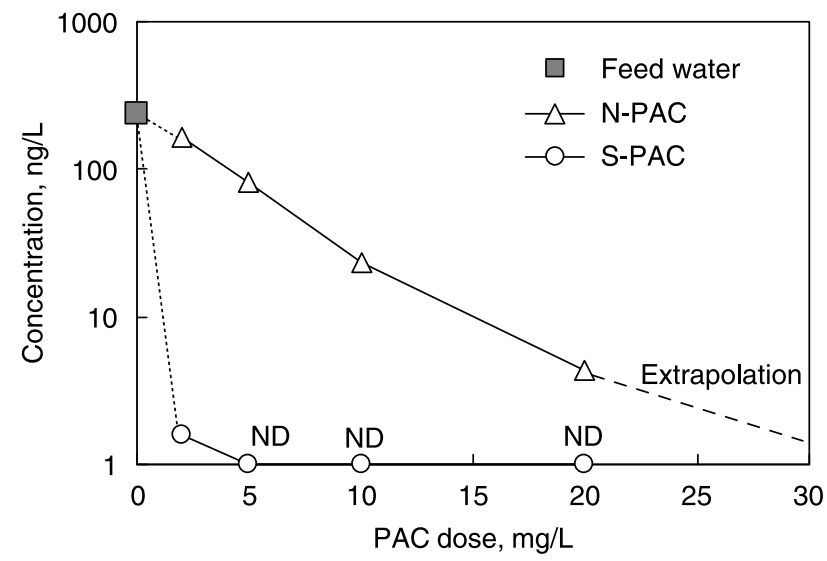

Figure 5 | Changes in geosmin concentration in MF filtrate with N-PAC or S-PAC dosage in reagent-geosmin-spiked water. Filtrate samples were taken $5 \mathrm{~min}$ after the start of filtration (PACl $0.5 \mathrm{mg}-\mathrm{A} 1 / \mathrm{L}$, MF flux $0.167 \mathrm{~m} / \mathrm{h}$, backwash interval $3 \mathrm{~h}$ ). 
data). Therefore, PAC consumption can be reduced by more than $90 \%$ when S-PAC is used instead of N-PAC.

The results presented thus far were obtained with feed water spiked with synthetically produced reagent geosmin; this may not have accurately simulated raw water naturally contaminated with geosmin. Geosmin is a metabolite of blue-green algae and actinomycetes, and raw water containing natural geosmin typically contains geosmin producers (e.g., algae), extracellular organic matter, and other metabolites. To simulate such a system, laboratorycultured Anabaena was added to the feed tank, and a PACMF experiment was conducted at an S-PAC dosage of $2 \mathrm{mg} / \mathrm{L}$. Anabaena-spiked feed water had a geosmin concentration of $279 \mathrm{ng} / \mathrm{L}$, of which $84 \%$ was in the water phase and 16\% was still in the algal cells. At the beginning of a filtration cycle, the geosmin concentration in the membrane effluent was $9 \mathrm{ng} / \mathrm{L}$; after $3 \mathrm{~h}$ of filtration it had decreased to $4 \mathrm{ng} / \mathrm{L} \quad(>96 \%$ removal of water-phase geosmin) (Figure 6). The effluent geosmin concentration was actually higher than the concentration attained in the experiment with reagent geosmin, in which a geosmin concentration of less than $2 \mathrm{ng} / \mathrm{L}$ was attained with the same S-PAC dosage and a similar influent concentration. The difference in filtrate geosmin concentration suggests that the extracellular organic matter released from the algal cells may have influenced the adsorptive removal efficiency of the S-PAC.

With the use of Anabaena-spiked feed water, relationships similar to those shown in Figure 5 were obtained between the geosmin concentration of the membrane filtrate and the PAC dosage (Figure 7). The raw water contained geosmin at a concentration of $11 \mathrm{ng} / \mathrm{L}(7.7 \mathrm{ng} / \mathrm{L}$ in the water phase) and Anabaena culture was added to
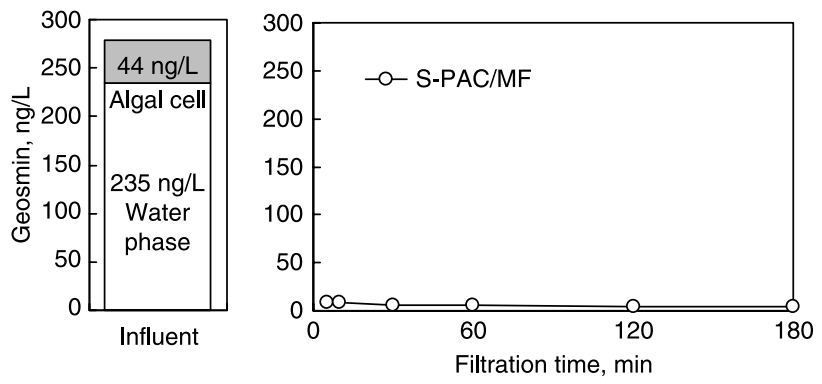

Figure 6 | Time-course change of geosmin concentration in MF filtrate from Anabaena-spiked water (S-PAC $2 \mathrm{mg} / \mathrm{L}, 1.3 \mathrm{mg}-\mathrm{A} 1 / \mathrm{L}$, MF flux $0.125 \mathrm{~m} / \mathrm{h}$, backwash interval $4 \mathrm{~h}$. bring the geosmin concentration in the feed water to $181 \mathrm{ng} / \mathrm{L}(149 \mathrm{ng} / \mathrm{L}$ in the water phase and $32 \mathrm{ng} / \mathrm{L}$ in the algal cells). Whereas the addition of $2 \mathrm{mg} / \mathrm{L} \mathrm{N}$-PAC yielded an MF filtrate geosmin concentration of $56 \mathrm{ng} / \mathrm{L}$, the addition of S-PAC at the same dosage yielded a concentration of $18 \mathrm{ng} / \mathrm{L}$. Addition of N-PAC at a dosage of $10 \mathrm{mg} / \mathrm{L}$ yielded an MF filtrate geosmin concentration of $25 \mathrm{ng} / \mathrm{L}$, whereas a similar MF filtrate geosmin concentration $(28 \mathrm{ng} / \mathrm{L})$ was obtained with S-PAC at $10 \%$ of the N-PAC dosage (i.e., an S-PAC dosage of $1 \mathrm{mg} / \mathrm{L}$ was equivalent to an N-PAC dosage of $10 \mathrm{mg} / \mathrm{L}$ in terms of geosmin removal). The results of the reagent geosmin experiments (Figure 5) suggest that the S-PAC dosage required was about $6 \%$ of the N-PAC dosage. The difference in dosage savings may be attributed to the effect of the extracellular organic matter released from the algal cells in the Anabaena experiments; DOC increased from 0.8 to $1.5 \mathrm{mg} / \mathrm{L}$ after the addition of Anabaena culture to the feed water. Thus, the advantage of S-PAC over N-PAC in adsorptive pretreatment may be slightly attenuated by the higher DOC. In the Anabaena experiments (Figure 7), geosmin concentration with S-PAC addition did not fall below $10 \mathrm{ng} / \mathrm{L}$ because the S-PAC dosage was insufficient. However, the superiority of S-PAC over N-PAC was confirmed.

Although we expected high concentrations of naturally occurring geosmin in raw water and a long summer, the year

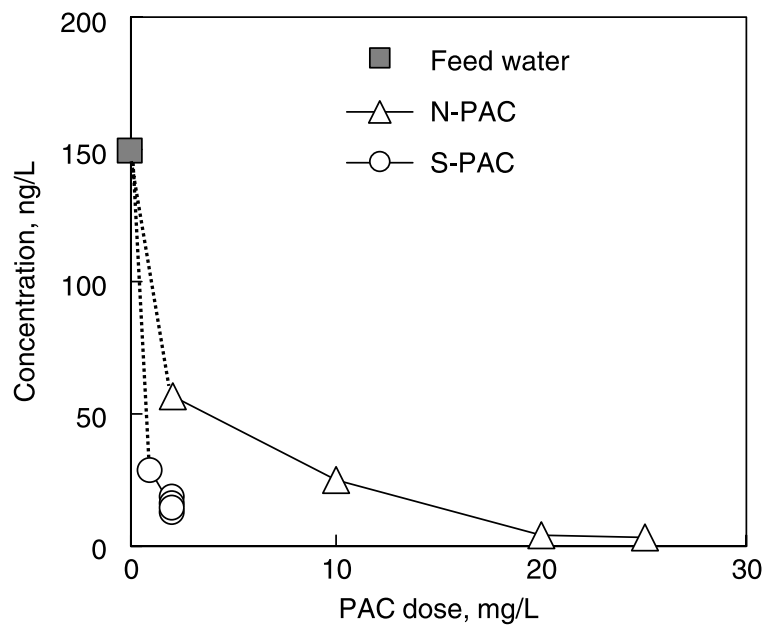

Figure $\mathbf{7}$ | Change in geosmin concentration in MF filtrate with PAC dosage in Anabaena-spiked water. Filtrate samples were taken $5 \mathrm{~m}$ after the start of filtration (PACl $1.2 \mathrm{mg}-\mathrm{A} 21 / \mathrm{L}, \mathrm{MF}$ flux $0.125 \mathrm{~m} / \mathrm{h}$, backwash interval $1 \mathrm{~h}$ ). 

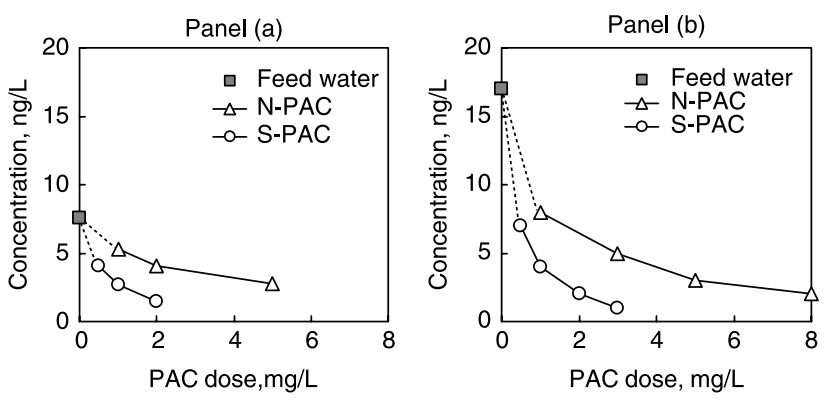

Figure 8 | Changes in geosmin concentration in MF filtrate with PAC dosage in the case of raw water containing naturally occurring geosmin. Filtrate samples were taken $5 \mathrm{~m}$ after the start of filtration. The raw water of panel (a) contained $7.4 \mathrm{ng} / \mathrm{L}$ water-phase geosmin and $6.6 \mathrm{ng} / \mathrm{L}$ in the algal cells. The raw water of panel (b) contained $17 \mathrm{ng} / \mathrm{L}$ water-phase geosmin and $2 \mathrm{ng} / \mathrm{L}$ in the algal cells (PACl $0.7 \mathrm{mg}-\mathrm{A} 1 / \mathrm{L}$, MF flux $0.125 \mathrm{~m} / \mathrm{h}$, backwash interval $1 \mathrm{~h}$ )

we conducted the experiment (2006) was rather unusual in that geosmin concentrations were low and the summer was short. We therefore conducted two experiments to confirm the superiority of S-PAC over N-PAC in mitigating naturally occurring geosmin although the concentrations were not high (Figure 8). The results shown in panel (a) of Figure 8 were obtained when the raw water had a water-phase geosmin concentration of $7.4 \mathrm{ng} / \mathrm{L}$ (total geosmin concentration was $14 \mathrm{ng} / \mathrm{L}$ ). The geosmin goal of the Waterworks Bureau, City of Yokohama, for water quality management is $3 \mathrm{ng} / \mathrm{L}$. The dosage of N-PAC required to reach this goal was $5 \mathrm{mg} / \mathrm{L}$, whereas an S-PAC dosage of $1 \mathrm{mg} / \mathrm{L}$ achieved the goal. The results shown in panel (b) were obtained when the raw water had a water-phase geosmin concentration of $17 \mathrm{ng} / \mathrm{L}$ (total geosmin concentration was $19 \mathrm{ng} / \mathrm{L}$ ). In this case, an N-PAC dosage of $8 \mathrm{mg} / \mathrm{L}$ was needed to reduce the geosmin concentration to $2 \mathrm{ng} / \mathrm{L}$, whereas an S-PAC dosage of $2 \mathrm{mg} / \mathrm{L}$ achieved the same concentration. These results confirm the superiority of S-PAC in mitigating naturally occurring geosmin. However, the dosage saving when using S-PAC was $75 \%$ to $80 \%$, which was lower than that observed in the experimental results with reagent geosmin and Anabaena-spiked waters. The difference in influent geosmin concentration may have affected the removal efficiency and thus the dosage saving. Further investigation and data analysis are required to confirm this hypothesis. However, we believe that the S-PAC dosage required should be $25 \%$ or less of the N-PAC dosage, for a dosage saving of 75\% or more.

Next we studied the effect of S-PAC addition on transmembrane pressure (TMP) build-up over the period
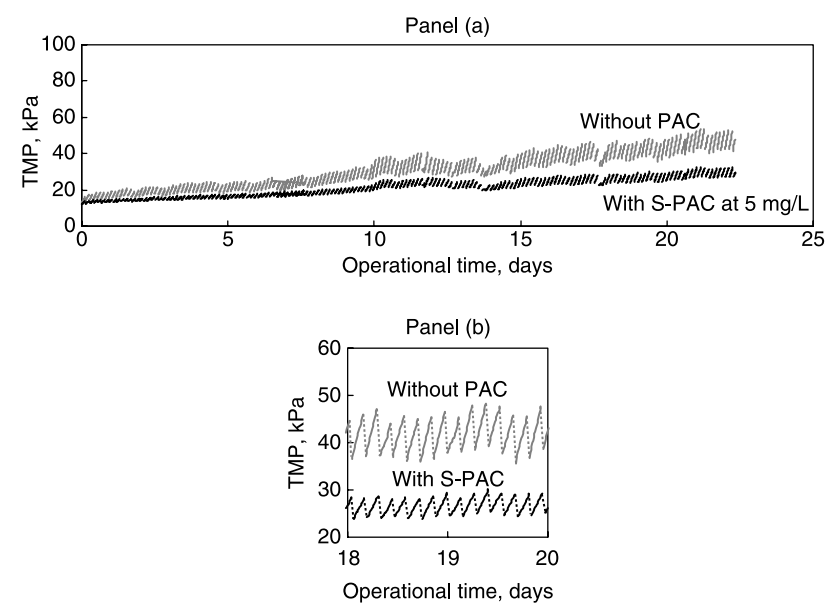

Figure 9 | (a) Transmembrane pressure (TMP) of MF membranes (PACl $0.5 \mathrm{mg}-\mathrm{A} 1 / \mathrm{L}$, MF flux $0.125 \mathrm{~m} / \mathrm{h}$, backwash interval $4 \mathrm{~h}$ ); (b) Changes in TMP in 2 days (a magnification of Figure 9a).

of operation by comparing MF runs with and without S-PAC. As shown in panel (a) of Figure 9a, the rates of TMP build-up over 22 days of operation were lower for MF with S-PAC than for MF without PAC, suggesting lower accumulation rate of membrane-fouling substances that can not be cleared by hydraulic backwash (irreversible membrane-fouling substances). This difference is probably due to the removal of membrane-fouling substances, such as natural organic matter, by S-PAC adsorption, before these substances could enter the membrane. A saw-toothed pattern in TMP change was observed (Figure 9a and magnified in Figure 9b). Every 4h, TMP increased and then dropped following the membrane hydraulic backwash. The TMP increase after each backwash until just before the next backwash (represented by the spikes) returned to approximately the same level. Therefore, the periodic TMP increase was mostly due to reversible membrane fouling. The periodic TMP increase was also smaller with S-PAC addition than without S-PAC (Figure 10). This may have been because 1) a reversible membrane foulant was adsorbed onto the S-PAC before the foulant could enter the membrane, so that the foulant load on the membrane was alleviated; and 2) floc particles with greater porosity were formed with S-PAC particles, so that cake layer buildup on the membrane surface was more permeable with S-PAC than without it. We have not yet confirmed the veracity of either or both of these reasons. Nonetheless, the 


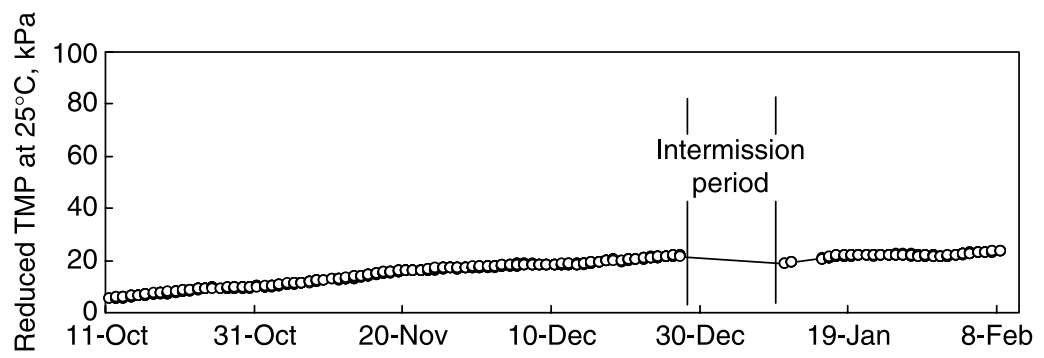

Figure 10 | Transmembrane pressure (TMP) in large-membrane MF operation (S-PAC $10 \mathrm{mg} / \mathrm{L}, \mathrm{PACl} 0.7 \mathrm{mg}-\mathrm{A} 1 / \mathrm{L}, \mathrm{MF}$ flux 0.125 m/h, backwash interval $4 \mathrm{~h}$ ).

experimental results indicate that S-PAC addition attenuated both reversible and irreversible membrane fouling.

The TMP pattern for the 22-day period (Figures 9a and 9b) was obtained with the small pilot system in which small membranes were used. Therefore, the hydraulics could not be exactly the same as those with the large membrane that is used in full-scale applications (Yonekawa 2004). Moreover, the experimental run time was limited to 22 days. When applying S-PAC before membrane filtration, long-term TMP build-up, possibly because of fouling or clogging of the membrane surface by S-PAC particles, is an important concern. Therefore, we conducted a long-term pilot test with a large membrane to evaluate the hydraulic effect of S-PAC on membrane permeability. The plant with the large membrane operated successfully for 4 months without an excessive increase in TMP (Figure 10). The wet bead-mill was automatically operated intermittently to pulverise N-PAC to produce S-PAC, and the S-PAC slurry was injected before membrane filtration. On-site S-PAC production as well as the S-PAC-MF system operated satisfactorily.

\section{CONCLUSION}

We conducted a small-scale pilot plant experiment to study the S-PAC-MF system to mitigate earthy-musty taste and odours caused by the presence of geosmin in drinking water. S-PAC adsorption pretreatment before MF successfully removed geosmin with a lower PAC dosage than in the case of N-PAC adsorption pretreatment. The dosage saving by using S-PAC rather than N-PAC was at least 75\%. The long-term MF run with S-PAC pretreatment confirmed that the S-PAC-MF system can be operated without excessive TMP increase, suggesting that membrane fouling caused by
S-PAC particle clogging did not occur or was negligible. Both TMP build-up during filtration cycles (i.e., between backwashes) and long-term TMP build-up caused by irreversible membrane fouling were mitigated by the addition of S-PAC to the MF feed water.

\section{$\overline{\text { ACKNOWLEDGEMENTS }}$}

The authors thank Mr. Nagai and Mr. Suzuki of the Waterworks Bureau, City of Yokohama, for their assistance in organising this research project. This study was conducted in part as an unsolicited study of the e-Water Project of the Japan Water Research Center. It was partly supported by research grants from the Ministry of Health, Labour and Welfare and the Ministry of Education, Science, Sports and Culture of the Government of Japan.

\section{$\overline{\text { REFERENCES }}$}

Baudin, I., Anselme, C. \& Chevalier, M. R. 1993 The removal of turbidity and taste and odour problems in drinking wateradvantages of the ultrafiltration process. J. Water SRT - Aqua 42(5), 295-300.

Castaldelli, G., Mantovani, S., Benvenuti, M. R., Rossi, R. \& Fano, E. A. 2005 Invertebrate colonisation of GAC filters in a potabilisation plant treating groundwater. J. Water SRT Aqua 54, 561-568.

Clark, M. M., Baudin, I. \& Anselme, C. 1996 Membrane-powdered activated carbon reactors. In: Mallevialle, J. (ed.) Water Treatment Membrane Processes. McGraw-Hill, New York, USA, pp. 15.1-15.22.

Japan Water Works Assoc. 20or Standard Method for the Examination of Water. Tokyo (in Japanese).

Japan Water Works Assoc. 2006 National Census on Water Supply Facilities and the Waterworks Statistics 2005 (No.87). Tokyo (in Japanese). 
Laine, J.-M., Glucina, K., Malleret, L., Bruchet, A., Baudin, I. \& Jacangelo, J. G. 200I Assessment of membrane processes for taste and odour removal. Water Sci. Technol.: Water Supply 1(4), 19-24.

Lefebvre, E., Racaud, P., Parpaillon, Th. \& Deguin, A. 1995 Results of bromide and bromate monitoring at several water treatment plants. Ozone Sci. Eng. 17(3), 311-327.

Matsui, Y., Murase, R., Sanogawa, T., Aoki, N., Mima, S., Inoue, T. \& Matsushita, T. 2004 Micro-ground powdered activated carbon for effective removal of natural organic matter during water treatment. Water Sci. Technol.: Water Supply 4(4), 155-163.

Matsui, Y., Murase, R., Sanogawa, T., Aoki, N., Mima, S., Inoue, T. \& Matsushita, T. 2005 Rapid adsorption pretreatment with submicron powdered activated carbon particles before microfiltration. Water Sci. Technol. 51(6-7), 249-256.
Matsui, Y., Sanogawa, T., Aoki, N., Mima, S. \& Matsushita, T. 2006 Evaluating submicron-sized activated carbon adsorption for microfiltration pretreatment. Water Sci. Technol: Water Supply 6(1), $149-155$.

Ministry of Health, Labour and Welfare of Japanese Government 2006 http://www.mhlw.go.jp/topics/bukyoku/kenkou/suido/ jouhou/suisitu/pdf/o5.pdf (in Japanese).

Proc. IWSA International Workshop on Bromates and Water Treatment. Paris, Nov. 1993.

Watanabe, M. M. \& Ichimura, T. 1977 Fresh- and salt-water forms of Spirulina platensis in axenic cultures. Bull. Jpn. Soc. Phycol. 25(Suppl.), 371-377.

Yonekawa, H., Tomita, Y. \& Watanabe, Y. 2004 Behavior of micro-particles in monolith ceramic membrane filtration with pre-coagulation. Water Sci. Technol. 50(12), 317-325.

First received 5 April 2007; accepted in revised form 19 June 2007 